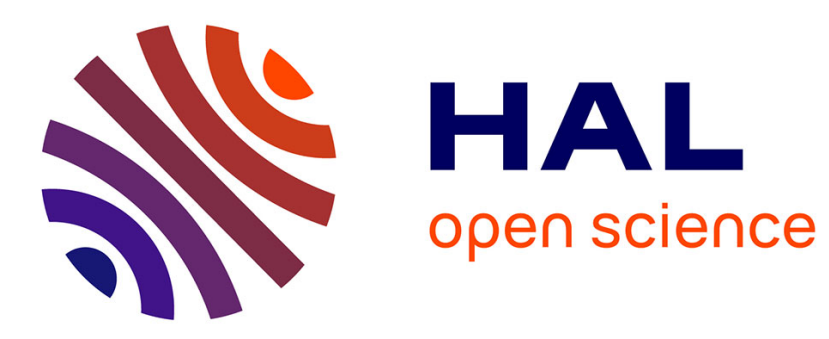

\title{
Oxidation-Sensitive Polymersomes Based on Amphiphilic Diblock Copolypeptoids
}

Yangwei Deng, Hui Chen, Xinfeng Tao, Fangyi Cao, Sylvain Trépout, Jun Ling, Min-Hui Li

\section{- To cite this version:}

Yangwei Deng, Hui Chen, Xinfeng Tao, Fangyi Cao, Sylvain Trépout, et al.. Oxidation-Sensitive Polymersomes Based on Amphiphilic Diblock Copolypeptoids. Biomacromolecules, 2019, 20 (9), pp.34353444. 10.1021/acs.biomac.9b00713 . hal-03051829

\section{HAL Id: hal-03051829 \\ https://hal.science/hal-03051829}

Submitted on 22 Dec 2020

HAL is a multi-disciplinary open access archive for the deposit and dissemination of scientific research documents, whether they are published or not. The documents may come from teaching and research institutions in France or abroad, or from public or private research centers.
L'archive ouverte pluridisciplinaire HAL, est destinée au dépôt et à la diffusion de documents scientifiques de niveau recherche, publiés ou non, émanant des établissements d'enseignement et de recherche français ou étrangers, des laboratoires publics ou privés. 


\section{Oxidation-Sensitive Polymersomes Based on 2 Amphiphilic Diblock Copolypeptoids}

3 Yangwei Deng, ${ }^{\dagger,+}$ Hui Chen,${ }^{\dagger}$ Xinfeng Tao,,${ }^{+}{ }^{\perp}$ Fangyi Cao,,${ }^{+}$Sylvain Trépout,,

4 Jun Ling, *,t and Min-Hui Li ${ }^{*, t, *, \xi}$

5 Chimie ParisTech, PSL University Paris, CNRS, Institut de Recherche de Chimie Paris,

6 UMR8247, 11 rue Pierre et Marie Curie, 75005 Paris, France

7 MOE Key Laboratory of Macromolecular Synthesis and Functionalization, Department of

8 Polymer Science and Engineering, Zhejiang University, 38 Zheda Road, 310027 Hangzhou,

9 China

$10{ }^{\S}$ Beijing Advanced Innovation Center for Soft Matter Science and Engineering, Beijing

11 University of Chemical Technology, 15 North Third Ring Road, Chaoyang District, 100029

12 Beijing, China

13 "Institut Curie, INSERM U1196 and CNRS UMR9187, 91405 Orsay cedex, France

14 *Correspondence: min-hui.li@chimieparistech.psl.eu (M.-H.L), lingjun@zju.edu.cn (J.L.)

15 KEYWORDS: polypeptoid; self-assembly; polymersome; oxidation-responsive;

16 light-responsive 


\section{ABSTRACT}

3 Stimuli-responsive polymersomes formed by amphiphilic block copolymers have attracted

4 substantial attention as smart and robust containers for drug delivery and

5 nano/micro-reactors. Bio-sourced amphiphilic diblock copolypeptoids were developed that

6 can self-assemble into oxidation-responsive unilamellar vesicles. These vesicles can burst

7 under the action of reactive oxygen species which can be the hydrogen peroxide, or the

8 singlet oxygen produced by light-activation of photosensitizer with spatiotemporal control.

9 Polysarcosine (PSar, also called poly( $N$-methyl glycine)) was selected as the hydrophilic

10 block, due to its resistance to protein adsorption and low toxicity, similar to PEG. We

11 designed and synthesized poly( $N$-3-(methylthio)propyl glycine) as the hydrophobic block. Its

12 polyglycine backbone is the same as that of PSar, and especially its hydrophobic

$13 N$-substituents, thioether side-chains, can be oxidized to hydrophilic sulfoxides. These

14 oxidation-responsive polymersomes entirely based on $N$-substituted poly(amino acid)s were

15 biocompatible as confirmed by cell viability tests, and may find applications in drug delivery,

16 biosensing, biodetection, and nano-/micro-reactors. 


\section{INTRODUCTION}

2 Polymersomes are stable and robust vesicles made of amphiphilic block copolymers. ${ }^{1}$

3 Polymer chemistry enables almost unlimited molecular design of responsive polymersomes

4 whose rupture upon environmental changes can be used for the controlled release of active

5 substances. Moreover, targeted transport can be achieved by taking advantage of the many

6 possibilities to end-functionalize the copolymers. Therefore, polymersomes are good

7 candidates for carriers in drug delivery and bio-imaging, or for micro/nano-reactors to

8 conduct sophisticated and cascade catalytic reactions. ${ }^{2-5}$ For the potential applications in drug

9 delivery, controlled release of active species has been studied through the use of copolymers

10 that respond to stimuli like reduction, oxidation, $\mathrm{pH}$ changes, temperature variation, shear

11 stress, and light illumination. ${ }^{6-14}$ Among these stimuli, the reactive oxygen species (ROS)

12 existing in high concentration within tumors and inflammatory tissues present special

13 interests and have been used as effective triggers to develop oxidation-responsive polymer

14 nanostructures for target-specific therapeutic delivery. ${ }^{15-17}$ Hydrogen peroxide $\left(\mathrm{H}_{2} \mathrm{O}_{2}\right)$, singlet

15 oxygen $\left({ }^{1} \mathrm{O}_{2}\right)$, superoxide, and hydroxyl radicals are the most well studied ROS in cancer and

16 inflammatory diseases. ${ }^{18-21}$ These ROS can also be generated easily with spatiotemporal

17 control by in situ biochemical or photochemical reactions. ${ }^{22-23}$ For example, $\mathrm{H}_{2} \mathrm{O}_{2}$ can be

18 produced by the glucose-oxidase $(\mathrm{GOx}) /$ glucose/oxygen system and can induce

19 destabilization of oxidation-sensitive polymersomes. ${ }^{24}{ }^{1} \mathrm{O}_{2}$ and other ROS can be generated

20 under light illumination through photosensitizers incorporated in polymersomes and can 
1 eventually cause polymersome rupture and payload release. ${ }^{23,25-26}$ Here, we report the

2 ROS-activated bursting of polymersomes formed from the amphiphilic diblock

3 copolypeptoids that are $\mathrm{H}_{2} \mathrm{O}_{2}$-sensitive and also engineered to be light-responsive by the

4 incorporation of a photosensitizer.

5 The most common oxidation-sensitive polymers $^{27-29}$ include sulfur-containing aliphatic 6 polymers (polythioethers), ${ }^{30-33}$ selenium/tellurium-based polymers, $^{34-35}$ aryl

7 oxalate-containing polymers, ${ }^{36}$ and phenylboronic ester-containing polymers. ${ }^{37-38}$ In recent

8 years, there has been an emerging interest in polythioethers of both main-chain and

9 side-chain types, such as main-chain poly(propylene sulfide) (PPS), ${ }^{39}$ polyethylene glycol

10 with pendent thioethers, ${ }^{40}$ and polypeptides with pendent thioethers (poly(L-methionine) and

$11 S$-substituted poly(L-cysteine)). ${ }^{41-45}$ The hydrophobic thioether groups can be transformed

12 into more polar sulfoxide or sulfone groups under the oxidation by ROS, leading to a

13 significant increase of the water solubility of polymers. This solubility change results in a

14 modification of the hydrophobic/hydrophilic balance of amphiphilic copolymers containing

15 thioethers and causes the disassembly or dissolution of their polymersomes ${ }^{39}$ or polymer

16 micelles. ${ }^{44,46}$ In the present work, a bio-sourced side-chain polythioether was synthesized as a

17 polypeptoid with pendant $N$-substituted thioether (poly( $N$-3-(methylthio)propyl glycine,

18 PMeSPG), and their amphiphilic block copolymer poly( $N$-3-(methylthio)propyl

19 glycine)-block-polysarcosine (PMeSPG- $b$-PSar). PMeSPG- $b$-PSar was used to construct

20 polymersomes responsive to ROS (Scheme 1). 


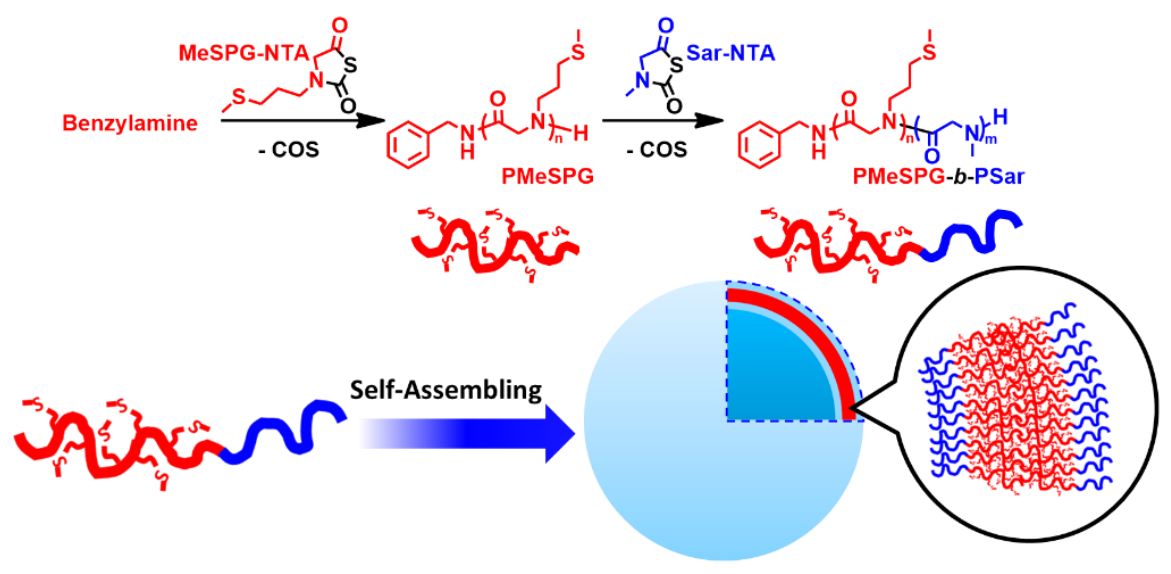

2

3 Scheme 1. Synthesis of PMeSPG- $b$-PSar block copolymers and their self-assembly into

4 polymersome.

5 Polypeptoids, as the derivatives of polypeptides without hydrogen on the amide groups, avoid

6 the formation of intra- and intermolecular hydrogen bonds. Consequently, polypeptoids

7 possess generally a random coil conformation in solution similar to common polymers and

8 show much better solubility in organic solvents compared to polypeptides. ${ }^{47}$ On the other

9 hand, polypeptoids, similar to polypeptides, maintain good biocompatibility and

10 biodegradability. ${ }^{48-52}$ PMeSPG and PSar (also named as poly( $N$-methyl glycine)) have a

11 shared polyglycine backbone with, respectively, methyl-S-propyl and methyl as the side chain

12 substituting for the hydrogen on the nitrogen atom. These compounds show the common

13 properties of polypeptoids. Moreover, PSar is a water soluble polypeptoid based on a natural

14 amino acid, which has been investigated for biomedical applications. ${ }^{53-55}$ With good protein

15 resistance, ${ }^{56-57}$ PSar is considered to be a potential alternative to poly(ethylene glycol) 
1 (PEG). ${ }^{58-59}$ Thus, PSar and PMeSPG represent interesting and useful alternatives to PEG and

2 poly(L-methionine)/poly(L-cysteine)/PPS as copolymer building blocks to prepare

3 oxidation-responsive self-assemblies for controlled drug delivery applications. Up to now,

4 reports of polymersomes based on polypeptoid-containing copolymers have been scarce. ${ }^{60-65}$

5 Here we report the first oxidation-responsive polymersomes made of amphiphilic block

6 copolypeptoids. As a typical ROS, $\mathrm{H}_{2} \mathrm{O}_{2}$ is produced at a rate of $5 \mathrm{nmol}$ per hour by ten

7 thousand units of cancer cells. ${ }^{66}$ The relatively high $\mathrm{H}_{2} \mathrm{O}_{2}$ concentration in tumor and

8 inflammatory tissues has been utilized in targeted drug delivery studies. ${ }^{67-68}$ In our work, $\mathrm{H}_{2} \mathrm{O}_{2}$

9 was first employed to assess the oxidation-sensitive property of the polymersomes. A

10 photosensitizer, tetraphenylporphyrin (TPP), was also introduced into the system of

11 polymersomes, which generated in situ ROS under illumination of visible light, and provoked

12 the rupture of polymersome. Our system may be useful in target-specific therapeutic delivery

13 and in the combination of chemotherapy and photodynamic therapy (PDT). ${ }^{69-70}$ Other

14 applications in biosensing, biodetection, and nano-/micro-reactors might be possible.

16 EXPERIMENTAL

17 Monomer, Homopolymer and Block-Copolymer Synthesis

18 To synthesize the $N$-substituted thioether-bearing glycine, MeSPG, the purchased

19 D,L-methionine (Sigma Aldrich) was firstly decarboxylated by reflux at $195{ }^{\circ} \mathrm{C}$ with the

20 catalysis of $\mathrm{R}-(-)$-carvone and then with hydrochloric acid. The aqueous solution of 
1 decarboxylated 3-(methylthio)propylamine (MeSPA) hydrochloride was then reacted with

2 glyoxylic acid under reflux. The MeSPG hydrochloride was obtained after the removal of

3 water. Sarcosine and MeSPG hydrochloride were, respectively, reacted with

4 S-ethoxythiocarbonylmercaptoacetic acid (XAA), and followed by $\mathrm{PBr}_{3}$-catalyzed

5 cyclization, to obtain the monomers Sar-NTA and MeSPG-NTA. Homopolymerization of

6 MeSPG-NTA was conducted in THF at $60{ }^{\circ} \mathrm{C}$, initiated by benzylamine with a controlled

7 feeding ratio. The block copolymers PMeSPG- $b$-PSar were synthesized by sequential ROP of

8 MeSPG-NTA and Sar-NTA using benzylamine as initiator. The detailed procedures and

9 characterizations are described in Supporting Information.

10 Vesicle Preparation

11 In nanoprecipitation method, typically, the copolymer was dissolved in $1 \mathrm{~mL}$ of DMF (at 0.5

12 wt \%). A total of $2 \mathrm{~mL}$ of deionized milli-Q water was injected slowly to the organic solution

13 under mild shaking (2-3 $\mu \mathrm{L}$ of water per minute to $1 \mathrm{~mL}$ of polymer solution). The process

14 of nanoprecipitation was carried out at $25^{\circ} \mathrm{C}$. The turbid mixtures were then dialyzed against

15 water for 3 days to remove DMF using a Spectra/Por regenerated cellulose membrane with a

16 molecular weight cutoff (MWCO) of 3500. In double emulsion method, copolymer was

17 firstly dissolved in chloroform at a concentration of $5 \mathrm{~g} / \mathrm{L}$, together with Nile Red at $0.05 \mathrm{~g} / \mathrm{L}$

18 (if applicable). Water $(10 \mu \mathrm{L})$ was added to $1 \mathrm{~mL}$ of the above solution. The mixture was then

19 treated by the homogenizer ULTRA-TURRAX T25, at the rate of $20000 \mathrm{rpm}$ for $5 \mathrm{~min}$, to

20 prepare $\mathrm{W} / \mathrm{O}$ inverse emulsion. W/O emulsion $(300 \mu \mathrm{L})$ was transferred to $3 \mathrm{~mL}$ water, and 
1 dispersed by the homogenizer at $5000 \mathrm{rpm}$ for $1 \mathrm{~h}$. The obtained W/O/W double emulsion

2 was heated at $50{ }^{\circ} \mathrm{C}$ with stirring (around $500 \mathrm{rpm}$ ) for $36 \mathrm{~h}$ to remove chloroform by

3 evaporation, resulting in the vesicle sample with polymer concentration of $0.5 \mathrm{~g} / \mathrm{L}$. For the

4 vesicle sample in $\mathrm{D}_{2} \mathrm{O}$ for ${ }^{1} \mathrm{H}$ NMR analysis, the copolymer/chloroform solution was

5 prepared at $50 \mathrm{~g} / \mathrm{L}$, and $400 \mu \mathrm{L}$ heavy $\mathrm{W} / \mathrm{O}$ emulsion was prepared and transferred to $2.5 \mathrm{~mL}$

6 heavy water $\left(\mathrm{D}_{2} \mathrm{O}\right)$. About $2 \mathrm{~mL}$ vesicle-in- $\mathrm{D}_{2} \mathrm{O}$ was finally obtained after chloroform

7 evaporation, with concentration at $10 \mathrm{~g} / \mathrm{L}$. For photo-activated experiments, TPP/dioxane

8 solution (in the case of ${ }^{1} \mathrm{H}$ NMR analysis) or TPP/THF solution (in the case of CLSM

9 observation) was added to the vesicle samples (volume ratio of $1: 100$ ) to obtain the "vesicle

$10+$ TPP" blend. The molar ratio was typically at $[\mathrm{TPP}]:[$ copolymer $]=2.00: 1$ and $[\mathrm{TPP}]:$

$11[\mathrm{MeSPG}]=1: 30$.

12 Cryo-Electronic Microscopy (cryo-EM)

13 Samples $(5 \mu \mathrm{L})$ were deposited onto a 200 mesh holey copper grid (Ted Pella Inc., U.S.A.)

14 and flash-frozen in liquid ethane cooled down at liquid nitrogen temperature. Cryo-EM

15 images were then acquired on a JEOL 2200FS energy-filtered (20 eV) field emission gun

16 electron microscope operating at $200 \mathrm{kV}$ using a Gatan ssCCD $2048 \times 2048$ pixels.

\section{Confocal Laser Scanning Microscopy (CLSM)}

18 For CLSM sample preparation, the coverslips were first treated with $N$-hydroxysuccinimide

19 (NHS). The NHS esters grafted on the surface of coverslips can trap PMeSPG- $b$-PSar

20 vesicles, through the reaction between NHS esters and amino groups at the end of PSar on the 
1 polymersome surface. This allows the immobilization of polymersomes during microscopic

2 analysis. A narrow chamber between a slide and a surface-modified coverslip was formed

3 using two plastic paraffin film (Parafilm M) strips as spacers. The vesicle dispersion was

4 introduced inside the chamber by capillarity. In oxidation experiments with $\mathrm{H}_{2} \mathrm{O}_{2}, \mathrm{H}_{2} \mathrm{O}_{2}$

5 aqueous solution (10 $\mu \mathrm{L}, 35 \mathrm{mM})$ was added by capillarity to the chamber together with

6 vesicle dispersion $(30 \mu \mathrm{L})$ to obtain a mixture with a final $\mathrm{H}_{2} \mathrm{O}_{2}$ concentration at $8.8 \mathrm{mM}$.

7 CLSM images were recorded with Leica TCS SP5 confocal scanning system equipped with a

$863 \times$ oil immersion objective. HeNe $543 \mathrm{~nm}$ laser (maximum working power at $1.5 \mathrm{~mW}$ ) was

9 employed as the excitation light to obtain the fluorescent images.

10 Cell Viability Test

11 Human vein endothelial cells and mouse embryonic fibroblast (NIH 3T3) cells were

12 purchased from the Center for Typical Culture Collection, Chinese Academy of Sciences

13 (Shanghai, China). Cells were maintained in high-glucose DMEM (Gibco), supplemented

14 with 10\% fetal bovine serum (FBS, Sijiqing Co., Ltd., Hangzhou, China), $100 \mu \mathrm{g} / \mathrm{mL}$

15 penicillin, and $100 \mu \mathrm{g} / \mathrm{mL}$ streptomycin, and cultured at $37{ }^{\circ} \mathrm{C}$ in a $5 \% \mathrm{CO}_{2}$ humidified

16 environment. $1.0 \times 10^{4}$ cells were seeded in a 96-well plate and cultivated over night to allow

17 cell attachment. The medium was replaced with fresh medium containing varying

18 concentrations of polymersomes C2. After $24 \mathrm{~h}$ incubation, the cells were carefully washed

19 with PBS and their viability was quantified using the MTT assay. ${ }^{71-73}$ The viability of cells 
1 treated with polymersomes-free medium was denoted as $100 \% .4$ replicates were used for cell

2 experiments.

3

4 RESULTS AND DISCUSSION

5 Synthesis of Oxidation-sensitive Homopolymer PMeSPG and Diblock Copolymer

$6 \quad$ PMeSPG- $b$-PSar

7 As poly(amino acid)s, polypeptoids can be synthesized by solid phase synthesis, ${ }^{74}$ ring 8 opening polymerization (ROP) of $N$-carboxyanhydrides $(\mathrm{NCA}),{ }^{75}$ and $\mathrm{ROP}$ of

$9 \mathrm{~N}$-thiocarboxyanhydride $(\mathrm{NTA}){ }^{76}$ The $N$-substituted glycine $N$-thiocarboxyanhydrides

10 (NNTAs) have recently emerged as promising monomers for polypeptoid preparation

11 because they can be prepared in open air, have a long shelf life in an inert atmosphere, and

12 can conduct well-controlled polymerization. ${ }^{77-81}$ In this work, the synthesis of a new NNTA

13 was introduced, as $\mathrm{N}$-3-(methylthio)propyl glycine NTA (MeSPG-NTA) bearing an

14 oxidizable thioether group (Scheme 1). The $N$-substituted thioether-bearing glycine, MeSPG,

15 was firstly synthesized from the natural amino acid methionine, through a sequential one-pot

16 "decarboxylation- $N$-carboxymethylation" procedure (Scheme S1). We implemented this

17 method, for the first time, to transfer the substituting group $\mathrm{R}$ of the amino acid from the

$18 C$-substituted position $(C$-R) to the $N$-substituted position $(N-\mathrm{R})$. A number of $N$-R glycines

19 can potentially be synthesized from natural amino acids using this approach. The monomers 
1 MeSPG-NTA and sarcosine-NTA (Sar-NTA) were then prepared from MeSPG and

2 sarcosine, respectively, as described previously (Section 3 in SI). ${ }^{78}$

3 The homopolymer $\mathrm{PMeSPG}_{84}$ was synthesized by benzylamine-initiated ring-opening

4 polymerization of MeSPG-NTA (Scheme S2). The block copolymers PMeSPG- $b$-PSar were

5 synthesized by feeding in sequence MeSPG-NTA and Sar-NTA in amine-initiated

6 polymerizations (Scheme 1, more details in Section 4, SI). ${ }^{79}$ The structures of the

7 homopolymer and block copolymers were confirmed by NMR, SEC, and MALDI-TOF

8 (Figure S2-S5). The compositions of two block copolymers PMeSPG $45-b$-PSar 65 (C1) and

$9 \quad \mathrm{PMeSPG}_{60}-b$-PSar 50 (C2) used in this study are summarized in Table S2.

10 We then investigated the thioether-to-sulfoxide modification of the homopolymer $\mathrm{PMeSPG}_{84}$

11 under a simple oxidation by $\mathrm{H}_{2} \mathrm{O}_{2}$. As shown in Figure $\mathrm{S} 11,{ }^{1} \mathrm{H}$ NMR spectra of PMeSPG 84

12 before and after a 90-min treatment by $2.9 \mathrm{M} \mathrm{H}_{2} \mathrm{O}_{2}$ (10 wt\%) (Section 7 in SI) indicated

13 clearly the reaction from thioether to sulfoxide, in comparison with the spectra of

14 polymethionine sulfoxides reported previously. ${ }^{82}$

\section{Nano-Polymersomes and Their Destruction by Oxidation}

16 Two copolymers PMeSPG $45-b$-PSar 65 (C1) and PMeSPG $60-b$-PSar 50 (C2) (Table S2) were

17 chosen for the preparation of polymersomes, since their hydrophilic weight ratios $(41 \%$ and

$1829 \%$, respectively) were favorable for vesicle formation. ${ }^{83}$ Nanoscale vesicles of diameter of

19 100-250 nm, together with lamellae and spherical/cylindrical micelles, were obtained by 
1 nanoprecipitation (Section 5 in SI). Figure 1A and Figure S6 show the images of cryogenic

2 electronic microscopy (cryo-EM) of the $\mathrm{C} 1$ self-assemblies, where the process of vesicle

3 formation was detectable with the semi-closed vesicle (as shown by the arrow). The C1

4 self-assemblies obtained by nanoprecipitation exhibited non-ergodic characteristics and some

5 intermediate morphologies, like the semi-closed vesicle in the form of a pulled bag from the

6 closure of the lamellae, were kinetically frozen (detailed discussion in Section 5, SI). The

7 thickness of the hydrophobic part of the membrane was estimated to be $12 \pm 1 \mathrm{~nm}$, based on

8 high-resolution cryo-EM image showing the electron-dense (darker) edges of the membrane.

9 The contour length of the hydrophobic part (PMeSPG 45$)$ was calculated as $17.6 \mathrm{~nm}$ using the

10 MeSPG unit length of $3.9 \AA$ obtained by modelling an oligomer of 8 repeat units after the

11 MM2 energy minimization with the software Chem3D (Figure S8). We noted that the

12 membrane thickness was much lower than the sum of the lengths of two stretched chains

$13(35.2 \mathrm{~nm})$. Therefore, the conformation of the hydrophobic chain PMeSPG should be

14 coil-like in the membrane and the membrane has a unilamellar bilayer structure where the

15 chain entanglement would be possible between two leaflets.

16 The $\mathrm{C} 1$ self-assemblies were then treated with $2.9 \mathrm{M} \mathrm{H}_{2} \mathrm{O}_{2}(10 \mathrm{wt} \%)$ (more details in Section

17 7, SI). After the treatment no vesicle was observed under cryo-EM. Instead, only a very few

18 loose irregular clusters were detected (Figure 1B), which were probably the residues left by

19 the oxidized vesicles. The oxidation of the $\mathrm{C} 1$ self-assemblies was also followed by the

20 evolution of the count rates measured by dynamic light scattering (DLS) in kilo counts per 
1 second (kcps). The count rates represent the scattering intensity and indicate the size and/or

2 concentration of particles. The count rates decreased exponentially upon the addition of $\mathrm{H}_{2} \mathrm{O}_{2}$

3 with a characteristic time $\tau=20.2 \mathrm{~min}$ (Figure 1C). The decline in count rates can be

4 explained by the decrease in the size and/or concentration of the self-assemblies. After a

5 60-min or longer treatment, the count rates decreased to less than $100 \mathrm{kcps}$, the limit below

6 which the size measurement becomes unreliable. The evolution of count rates confirmed the

7 disruption of vesicles and other self-assemblies upon oxidation by $\mathrm{H}_{2} \mathrm{O}_{2}$. The variation of

8 count rate was also analyzed with lower concentration of $\mathrm{H}_{2} \mathrm{O}_{2}$, such as $8.8 \mathrm{mM}$ and $88 \mathrm{mM}$

9 (Figure S12). The count rates also declined along with the oxidation time, but more slowly

10 with a characteristic time $\tau=288.8 \mathrm{~min}$ and $112.8 \mathrm{~min}$ for $\mathrm{H}_{2} \mathrm{O}_{2}$ concentration of $8.8 \mathrm{mM}$ and

$1188 \mathrm{mM}$, respectively.

A
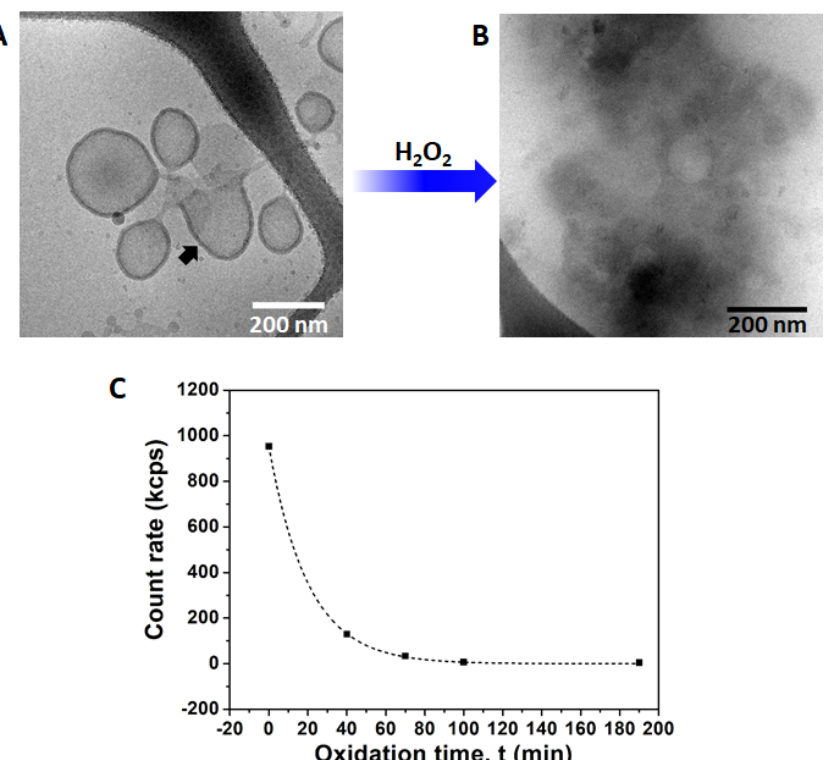

13 Figure 1. (A) Cryo-EM images of self-assemblies $\mathrm{C} 1$ obtained by nanoprecipitation before 14 any treatment. (B) Self-assemblies $\mathrm{C} 1$ after 90 -min of $2.9 \mathrm{M} \mathrm{H}_{2} \mathrm{O}_{2}(10 \mathrm{wt} \%)$ treatment. (C) 
1 The evolution of count rates of self-assemblies C1 measured by DLS as a function of the time

2 of treatment with $2.9 \mathrm{M} \mathrm{H}_{2} \mathrm{O}_{2}$. The symbols are the experimental points. The dashed line is

3 the fit with the exponential decay function $c=c_{\max } \mathrm{e}^{-\mathrm{t} / \tau}$, where $\mathrm{c}_{\max }$ is the maximum count rate

4 at $\mathrm{t}=0$, and $\tau=20.2 \mathrm{~min}$ is the characteristic time for $\mathrm{c}$ to decrease to $36.8 \%$ of $\mathrm{c}_{\max }$.

\section{Giant Polymersomes and Their Destruction by Oxidation}

6 To address in more detail the oxidation-responsive transformation of the vesicular

7 morphology, we prepared micrometer-sized giant vesicles and then followed their disruption

8 under the oxidation of $\mathrm{H}_{2} \mathrm{O}_{2}$ in situ using confocal laser scanning microscopy (CLSM). An

9 emulsion-mediated approach through water-in-oil-in-water $(\mathrm{W} / \mathrm{O} / \mathrm{W})$ double emulsion ${ }^{84-86}$

10 was employed to prepare giant vesicles (see SI and Figure S9). Both block copolymers C1

11 and C2 can form giant vesicles by this double emulsion method. As the vesicles obtained

12 from $\mathrm{C} 2$ have larger sizes compared to those from $\mathrm{C} 1, \mathrm{C} 2$ was chosen to make giant

13 polymersomes in the following studies for their easier optical observation by CLSM. The

14 obtained polymersomes $\mathrm{C} 2$ had a wide size distribution from 0.5 to $20 \mu \mathrm{m}$ in diameter

15 (Figure 2A). The relatively small vesicles among them were trapped successfully in the

16 sample grid by the rapid vitrification for cryo-EM imaging (Figure 2B and Figure S10). Their

17 membrane thickness measured as around $12 \mathrm{~nm}$, which is consistent with a unilamellar

18 bilayer structure of amphiphilic block copolymer C2 as discussed above. 
1 The sample of giant polymersomes labeled with Nile Red (1 wt $\%)$ was placed between a

2 slide and a surface-modified coverslip to observe the response of polymersomes to $\mathrm{H}_{2} \mathrm{O}_{2}$

3 oxidation under CLSM (more details in SI for CLSM experiments and surface treatment

4 procedure). The disruption of $\mathrm{C} 2$ vesicles was initiated by the addition of $\mathrm{H}_{2} \mathrm{O}_{2}$. Typically, 10

$5 \mu \mathrm{L}$ of $35 \mathrm{mM} \mathrm{H}_{2} \mathrm{O}_{2}(0.12 \mathrm{wt} \%)$ was added into $30 \mu \mathrm{L}$ of polymersome dispersion (60 wt $\%$ of

6 copolymer), resulting in a final concentration of $8.8 \mathrm{mM}$ for $\mathrm{H}_{2} \mathrm{O}_{2}(0.03 \mathrm{wt} \%)$ and a molar

7 ratio of $\left[\mathrm{H}_{2} \mathrm{O}_{2}\right]:[\mathrm{MeSPG}]=3.62: 1$. We observed two pathways in the vesicle disruption.

8 Figure $2 \mathrm{D}$ and Movie $\mathrm{S} 1$ (in SI) present the pathway $\mathrm{I}^{\mathrm{O}}$ (the superscript ${ }^{\mathrm{O}}$ indicate the trigger

9 is $\mathrm{H}_{2} \mathrm{O}_{2}$ ): the initial polymersome appears floppy with some slight membrane undulation; it

10 becomes well-rounded after $89 \mathrm{~s}$ of treatment; then the membrane fluctuates with more and

11 more turbulence and many pores appear on the vesicle surface, which finally leads to the

12 bursting of the polymersome. The whole procedure takes 4 min. The pathway $\mathrm{II}^{\mathrm{O}}$ (Figure $2 \mathrm{E}$

13 and Movie S2 in SI) also starts by the transformation from a floppy vesicle to a well-rounded

14 vesicle (achieved after around $282 \mathrm{~s}$ of $\mathrm{H}_{2} \mathrm{O}_{2}$ treatment), but is followed by the slow

15 shrinkage of the vesicle to a smaller size and outward budding in the final stage. The pathway

$16 \mathrm{II}^{\mathrm{O}}$ takes a longer time than the pathway $\mathrm{I}^{\mathrm{O}}$, with over 13 min passing before the vesicle

17 shrinks out of focus. The change from undulating and floppy vesicle to well-rounded vesicle

18 in both pathways can be explained by the decrease of the membrane surface caused by the

19 first fraction of polymers changing from amphiphilic to water soluble upon the oxidation of

20 thioether to sulfoxide. It was noticed that the vesicle following the pathway $\mathrm{II}^{\mathrm{O}}$ is not alone, 
1 but some small solid particles sticking on its surface. These solid particles can play the role of

2 the reservoir of initial copolymer PMeSPG- $b$-PSar to repair the pores left by the solubilized

$3 \mathrm{PMeSPG}^{\mathrm{O}}-b$-PSar in the membrane, because they may present multilamellar structures and

4 can only be attacked by $\mathrm{H}_{2} \mathrm{O}_{2}$ much more slowly. We interpret this behavior as a kind of

5 self-healing process that is absent in the pathway $\mathrm{I}^{\mathrm{O}}$. This healing process may explain the

6 more progressive reduction of the vesicle surface area and of the whole vesicle size in

7 pathway $\mathrm{II}^{\mathrm{O}}$.

8

$9 \quad$ Figure 2. (A) Bright-field optical microscopy image of polymersomes C2 prepared by double emulsion method. (B) Cryo-EM image of small vesicles among polymersomes C2. (C)

12 recordings of the vesicle disruption under the action of $8.8 \mathrm{mM} \mathrm{H}_{2} \mathrm{O}_{2}$ with the molar ratio of

$13\left[\mathrm{H}_{2} \mathrm{O}_{2}\right]:[\mathrm{MeSPG}]=3.62: 1$. Two different pathways are observed. (D) Pathway $\mathrm{I}^{\mathrm{O}}:$ the

14 vesicle turns first from an undulating and floppy vesicle to a well-rounded vesicle in the first 
$189 \mathrm{~s}$, then the membrane starts to fluctuate more and more intensely and many pores appear

2 around the vesicle surface (209 s) leading finally to vesicle bursting (225 s). (E) Pathway II ${ }^{\mathrm{O}}$ :

3 the vesicle changes first from an undulating and floppy vesicle to well-rounded vesicle in the

4 first $282 \mathrm{~s}$, but followed by the slow shrinkage of the vesicle to smaller size (example at 560

5 s) and outward budding in the final stage (754 s). Scale bar $=25 \mu \mathrm{m}$.
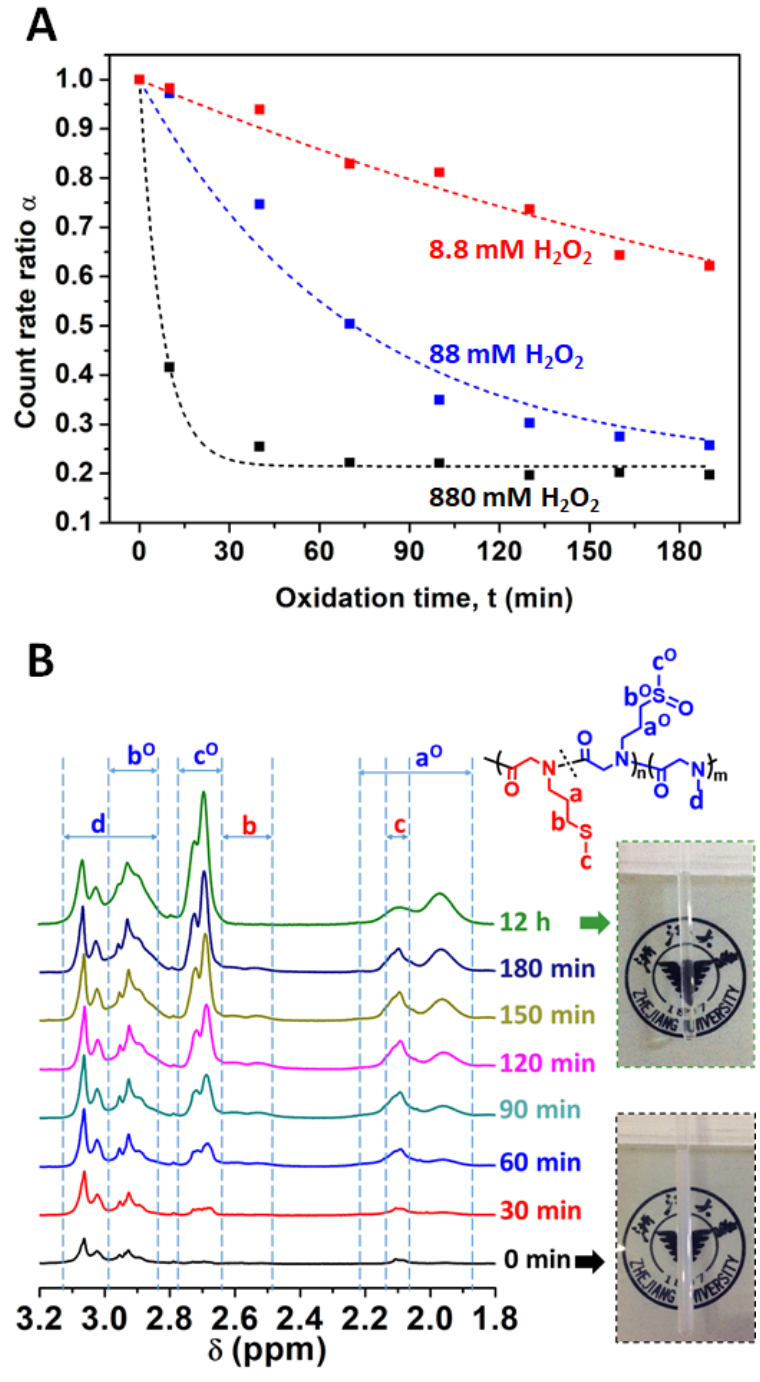

7 Figure 3. (A) The ratio of count rates $\alpha(\alpha=($ count rates at the time $t) /($ count rate at $t=0$

8 before $\mathrm{H}_{2} \mathrm{O}_{2}$ addition) of polymersomes $\mathrm{C} 2$ as a function of oxidation time $\mathrm{t}$, at different 
$1 \mathrm{H}_{2} \mathrm{O}_{2}$ concentrations $(8.8 \mathrm{mM}, 88 \mathrm{mM}$, and $880 \mathrm{mM})$. The symbols are the experimental

2 points. The lines are the fits with the function $\alpha=\left(1-\alpha_{\min }\right) \mathrm{e}^{-\mathrm{t} / \tau}+\alpha_{\min }$, where $\alpha_{\min }=0.215$ is

3 the minimum count rate ratio when the copolymers are totally oxidized, leaving a few

4 aggregates of Nile Red molecules, and $\tau$ is the characteristic time when $\left(\alpha-\alpha_{\min }\right)$ declines to

$536.8 \%$ of $\left(1-\alpha_{\min }\right) . \tau$ is $302.6 \mathrm{~min}, 70.6 \mathrm{~min}$, and $7.4 \mathrm{~min}$ for $\mathrm{H}_{2} \mathrm{O}_{2}$ concentration at $8.8 \mathrm{mM}$,

$688 \mathrm{mM}$, and $880 \mathrm{mM}$, respectively. (B) ${ }^{1} \mathrm{H}$ NMR spectra of polymersomes $\mathrm{C} 2$ obtained by

7 double emulsion in $\mathrm{D}_{2} \mathrm{O}$ in the presence of $176 \mathrm{mM} \mathrm{H}_{2} \mathrm{O}_{2}$ with the molar ratio of $\left[\mathrm{H}_{2} \mathrm{O}_{2}\right]$ :

$8 \quad[\mathrm{MeSPG}]=3.62: 1$. The photographs of the NMR sample tube beside the ${ }^{1} \mathrm{H}$ NMR spectra

9 show clearly the turbidity change (from turbid to transparent) of the polymersome dispersion

10 before and after oxidation. The logo is used with permission from Zhejiang University.

12 To confirm the chemical oxidation of copolymers under the conditions of CLSM observation,

13 the analyses by DLS was performed for giant polymersomes $\mathrm{C} 2$ treated by $8.8 \mathrm{mM} \mathrm{H}_{2} \mathrm{O}_{2}$.

14 The ratio of count rates $\alpha$ in Figure 3 represents the count rates at time $t$ normalized with

15 respect to count rates before $\mathrm{H}_{2} \mathrm{O}_{2}$ addition. The evolution of $\alpha$ as a function of time (Figure

$163 \mathrm{~A}$, red curve) supported the tendency of concentration/size of the self-assemblies to decrease

17 through the oxidation. We also examined the cases with higher $\mathrm{H}_{2} \mathrm{O}_{2}$ concentrations $(88 \mathrm{mM}$

18 and $880 \mathrm{mM}$ ). As shown in Figure 3A (blue and black curves), the value of $\alpha$ decreased more

19 rapidly when treated with higher $\mathrm{H}_{2} \mathrm{O}_{2}$ concentration. The decay of $\alpha$ under each condition

20 was fitted with an exponential function, giving the characteristic time $\tau$ of $302.6 \mathrm{~min}, 70.6$ 
$1 \mathrm{~min}$, and $7.4 \mathrm{~min}$ for $\mathrm{H}_{2} \mathrm{O}_{2}$ concentration at $8.8 \mathrm{mM}, 88 \mathrm{mM}$, and $880 \mathrm{mM}$, respectively. The

2 polymersome oxidation was also followed by ${ }^{1} \mathrm{H}$ NMR. For this analysis, polymersomes $\mathrm{C} 2$

3 was prepared by double emulsion using deuterium oxide $\left(\mathrm{D}_{2} \mathrm{O}\right)$ instead of water. The mixture

4 of polymersomes $\mathrm{C} 2$ and $\mathrm{H}_{2} \mathrm{O}_{2}$ has a concentration of $\mathrm{H}_{2} \mathrm{O}_{2}$ at $176 \mathrm{mM}$, but with the molar

5 ratio of $\left[\mathrm{H}_{2} \mathrm{O}_{2}\right]:$ [copolymer] $=217: 1$, and of $\left[\mathrm{H}_{2} \mathrm{O}_{2}\right]:[\mathrm{MeSPG}]=3.62: 1$ (the same molar

6 ratio as used in CLSM experiment). The evolution of ${ }^{1} \mathrm{H}$ NMR spectra as a function of

7 oxidation time is shown in Figure 3B (only the characteristic interval of chemical shift is

8 displayed). In general, the intensities of many signals tended to increase with time, either

9 because of the rise of mobility of polymers in the polymer assemblies upon oxidation such as

10 the signal $\mathrm{c}$ and signal $\mathrm{d}$, or because of the appearance of oxidized signals such as $\mathrm{a}^{\mathrm{O}}, \mathrm{b}^{\mathrm{O}}$ and

$11 \mathrm{c}^{\mathrm{O}}$. The signals assigned to the thioether eventually disappeared after sufficient oxidation

12 time (here $12 \mathrm{~h}$ ). The photographs of the NMR sample tube beside the ${ }^{1} \mathrm{H}$ NMR spectra show

13 clearly the turbidity changes of the polymersome dispersion. After $12 \mathrm{~h}$ of $\mathrm{H}_{2} \mathrm{O}_{2}$ treatment,

14 the initial turbid dispersion became transparent, confirming the transformation from giant

15 vesicles to solution of free polymers or of tiny aggregates.

16 Light-Activated Bursting of Giant Polymersomes

17 Having successfully prepared oxidation-sensitive giant polymersomes, we then searched for a

18 more controllable and more practical way to introduce the oxidation agents rather than the

19 direct addition of $\mathrm{H}_{2} \mathrm{O}_{2}$. The generation of ROS such as singlet oxygen $\left({ }^{1} \mathrm{O}_{2}\right)$ can be triggered

20 remotely and precisely by light. ${ }^{1} \mathrm{O}_{2}$ transformed from the ground state triplet oxygen $\left({ }^{3} \mathrm{O}_{2}\right)$ 
1 upon light illumination has been reported to destabilize liposomes ${ }^{87}$ and polymersomes. ${ }^{23,25}$,

$2{ }^{88-89}$ In a few examples, ${ }^{23,}{ }^{25}$ ROS thus produced reacted with thioether groups and provoked

3 the disassembly of polymersomes. The light-triggered rupture of polymersomes made of

4 PEG- $b$-PPS with a main-chain polythioether (poly(propylene sulfide)) has been shown to be

5 useful in precision intracellular delivery. ${ }^{23}$ Here, we explored photo-activated rupture of

6 PMeSPG- $b$-PSar polymersomes by introducing photosensitizers into the system.

7 The giant polymersomes C2 obtained from double emulsion method were blended with the

8 photosensitizer, tetraphenylporphyrin (TPP). ${ }^{25}$ TPP is a hydrophobic porphyrin, which emits

9 red fluorescence under visible light excitation and can be activated to transform dissolved

10 oxygen to ${ }^{1} \mathrm{O}_{2}$. TPP has a strong absorption band with maximum at $419 \mathrm{~nm}$ (so called Soret

11 band) and four weak bands with maxima at 515, 550, 593 and $649 \mathrm{~nm}$ (so called Q-bands). ${ }^{90}$

12 Visible lights and lasers in the Q-bands have been used frequently to activate the generation

13 of ${ }^{1} \mathrm{O}_{2} \cdot{ }^{25}$ The mixture of polymersomes $\mathrm{C} 2$ and TPP was prepared by adding $10 \mu \mathrm{L}$ TPP/THF

14 solution to $1 \mathrm{~mL}$ vesicle samples. As shown in Figure S13, the CLSM fluorescence image

15 confirmed that TPP molecules could attach on the surface of the polymersomes and might

16 enter by diffusion in the hydrophobic part of the membrane via hydrophobic interaction. The

17 evolution of ${ }^{1} \mathrm{H}$ NMR spectra was followed of polymersomes $\mathrm{C} 2$ loaded with TPP in $\mathrm{D}_{2} \mathrm{O}$ (10

$18 \mu \mathrm{L}$ TPP/1,4-dioxane solution was added to $1 \mathrm{~mL}$ polymersome $\mathrm{C}_{2} / \mathrm{D}_{2} \mathrm{O}$ sample, resulting in

19 the "vesicle + TPP" blend with the molar ratio of $[\mathrm{TPP}]:[\mathrm{MeSPG}]=1: 30)$ as a function of

20 the illumination time under white LED light with irradiance of $500 \mathrm{~mW} / \mathrm{cm}^{2}$ (Figure S14). 
1 The sample appearances in NMR tube before illumination and after 300 min of illumination

2 are also shown in Figure S14. Similar to the case of giant polymersomes treated by $\mathrm{H}_{2} \mathrm{O}_{2}$, the

3 transformation from thioether to sulfoxide, triggered here by light in the presence of

4 photosensitizer TPP, also led to the disassembly of giant polymersomes.

5 The in situ and real-time observation of the photo-activated polymersome opening was

6 performed by CLSM using the light source of the microscope as both observation and

7 activation tools. Giant polymersomes C2 labeled by Nile Red were first prepared and then

8 mixed with TPP solubilized in a tiny volume of THF (10 $\mu \mathrm{L}$ TPP/THF was added to $1 \mathrm{~mL}$

9 polymersome $\mathrm{C} 2 / \mathrm{D}_{2} \mathrm{O}$ sample, resulting in the "vesicle + TPP" blend with the molar ratio of

10 [TPP] : $[\mathrm{MeSPG}]=1: 30$ ). Figure 4B and Movie S3 (in SI) show the real-time evolution of

11 vesicles until disruption was provoked by the confocal laser $(543 \mathrm{~nm})$ of the microscope, with

12 the maximum working power of $1.5 \mathrm{~mW}$. The two vesicles in the view were disrupted

13 through two different pathways: the upper vesicle by pathway $\mathrm{I}^{\mathrm{L}}$ and the lower one by

14 pathway $\mathrm{II}^{\mathrm{L}}$ (the superscript $\mathrm{L}$ indicates the trigger is light, to distinguish from that of $\mathrm{O}$ with

$15 \mathrm{H}_{2} \mathrm{O}_{2}$ trigger in the previous section). In the pathway $\mathrm{I}^{\mathrm{L}}$, the vesicle size decreased slightly in

16 the first $37 \mathrm{~s}$, then the membrane fluctuated (until $118 \mathrm{~s}$ ) and subsequently opened at the

17 upper-right side with a micron-size pore and outward curling; the whole process of vesicle

18 disassembly required around $6 \mathrm{~min}$. In contrast, in the pathway $\mathrm{II}^{\mathrm{L}}$, the vesicle decreased its

19 size continuously until its disappearance and the whole process lasted $14 \mathrm{~min}$. The different

20 ways of disruption could be explained by the different distribution of TPP in these vesicles. If 
1 the distribution of TPP molecules around a vesicle was not homogeneous and more

2 concentrated in some places, high concentration of ${ }^{1} \mathrm{O}_{2}$ could be generated by TPP in these

3 places, which transformed locally many amphiphilic copolymers to water soluble polymers.

4 The subsequent removal of the water soluble chains from the membrane was so substantial

5 and rapid that the big pores left could not be healed by decreasing the vesicle surface and

6 diameter. Eventually, the vesicle burst rapidly after only $118 \mathrm{~s}$ of illumination. This is the

7 case of the pathway $\mathrm{I}^{\mathrm{L}}$. In contrast, in the case of the pathway $\mathrm{II}^{\mathrm{L}}$, TPP should be distributed

8 more uniformly at the vesicle surface; copolymers in the membrane were oxidized and

9 withdrawn at a rather constant and slower rate. Consequently, the membrane had time to heal

10 the pores by decreasing its surface area, leading to the slow and progressive shrinking of the

11 vesicle (over $14 \mathrm{~min})$. 
A

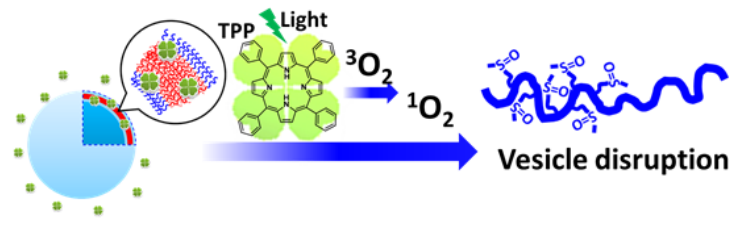

B
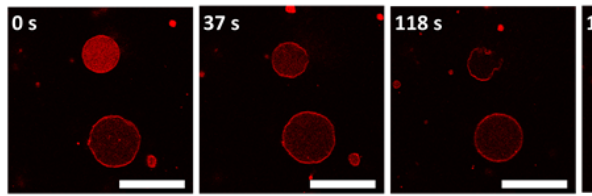

$134 \mathrm{~s}$
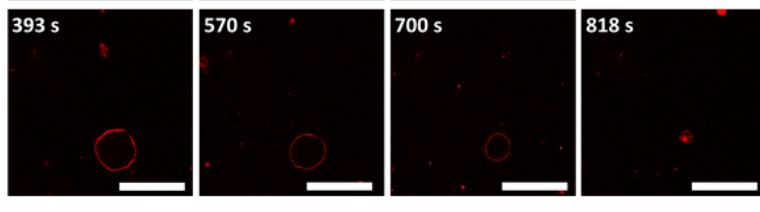

C
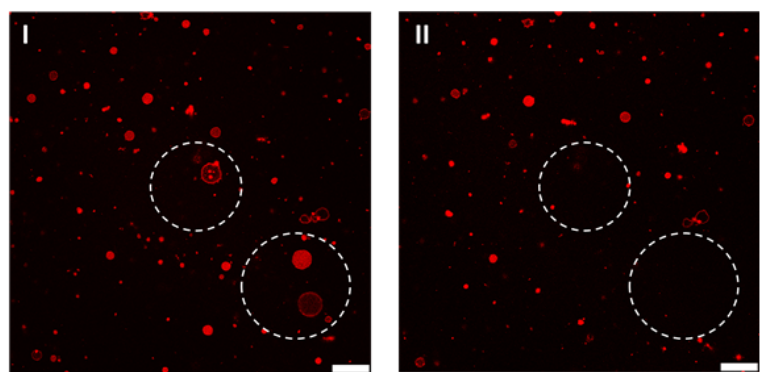

2 Figure 4. (A) The schematic illustration of the disruption process of $\mathrm{PMeSPG}_{60}-b-\mathrm{PSar}_{50}$

3 (C2) polymersome by singlet oxygen generated from light-activated TPP. (B) Snapshots of

4 the sequence of evolution of two polymersomes C2 labeled with Nile Red and loaded with

5 TPP (the molar ratio of $[\mathrm{TPP}]:[\mathrm{MeSPG}]=1: 30$ ) under the illumination of the confocal

6 laser $(543 \mathrm{~nm})$ of CLSM at the power of $1.5 \mathrm{~mW}$. Two pathways are observed for the

7 polymersome disruption. Scale bar $=25 \mu \mathrm{m}$. (C) The CLSM images of a large area (I) before

8 the observation and (II) after the observation of around $15 \mathrm{~min}$ with two focused spots

9 marked by the circles as described in (B). The vesicles under the focus disappear, while those

10 in other regions remain. Scale bar $=25 \mu \mathrm{m}$. 
1 The photo-activated bursting of polymersomes can also be controlled locally with the

2 precision of micrometers. Figure 4D shows the CLSM images of a large area (I) before the

3 observation and (II) after the observation of around 15 min with two focused spots marked by

4 circles (conditions as described in Figure 4C). The vesicles under the focus area disappeared,

5 while those in other regions remained. During the photo capture and video recording, these

6 two focused regions received more laser dose and produced more ROS leading to the vesicle

7 disruption. This observation suggests that the oxidation-responsive PMeSPG- $b$-PSar vesicles

8 can be opened or destroyed selectively in a controllable way through the manipulation of

9 laser irradiation.

\section{Cell Viability Test}

11 For the potential biomedical applications of PMeSPG- $b$-PSar polymersomes, we assessed

12 their biocompatibility using cell viability test with MTT as the indicator. Two kinds of cells,

13 human vein endothelial cells (ECs) and mouse embryonic fibroblast cells (MEFs), were

14 incubated, respectively, with the polymersomes C2 obtained from double emulsion. Different

15 concentrations of polymersomes such as $31.25,62.50,125.0,250.0,500.0$ and $1000 \mu \mathrm{g} / \mathrm{mL}$

16 were tested. As presented by the histogram in Figure 5, the tested cells maintained the relative

17 viability above $80 \%$ after $24 \mathrm{~h}$ of incubation, even with the polymersome suspension at a

18 concentration as high as $1 \mathrm{mg} / \mathrm{mL}$. These observations confirmed reliable biocompatibility of

19 PMeSPG- $b$-PSar copolymers and their polymersomes. 


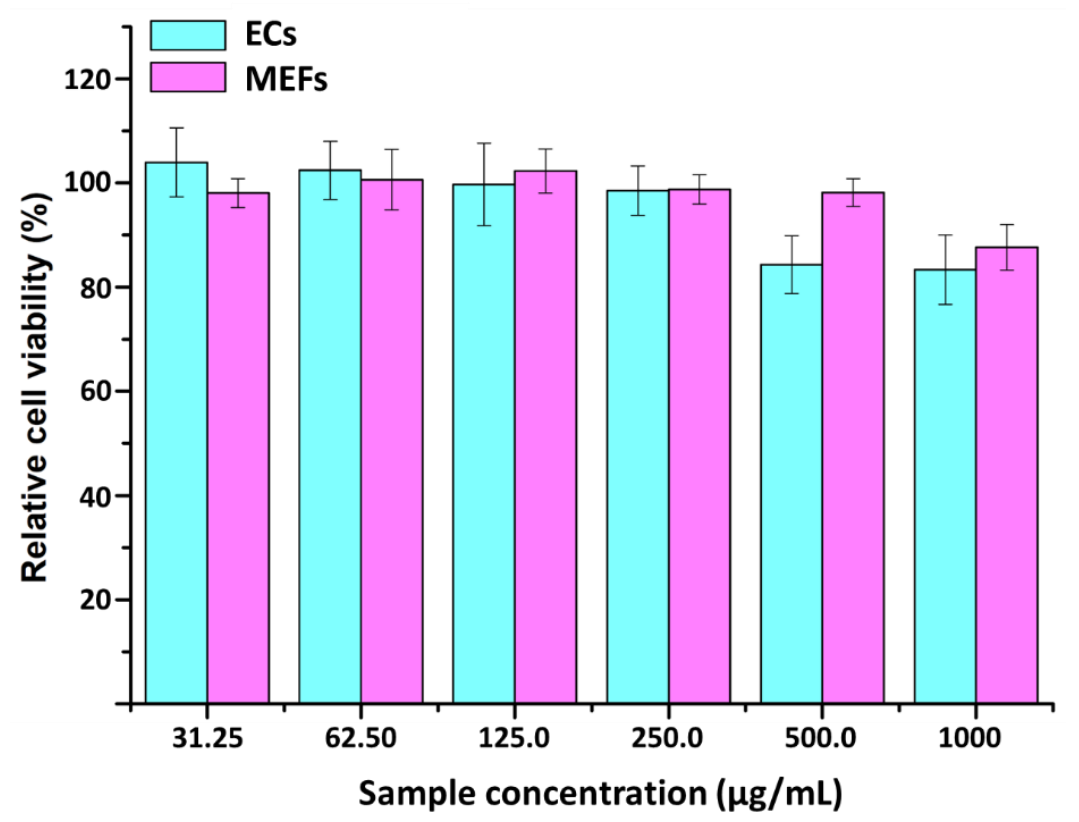

2 Figure 5. Relative cell viability of polymersomes $\mathrm{C} 2$ obtained from double emulsion, for

3 human vein endothelial cells (ECs) and mouse embryonic fibroblast cells (MEFs), after $24 \mathrm{~h}$

4 of incubation at $37{ }^{\circ} \mathrm{C}$ and at sample concentrations of $31.25,62.50,125.0,250.0,500.0$ and $5 \quad 1000 \mu \mathrm{g} / \mathrm{mL}$.

6

7 CONCLUSION

8 In this work, the synthesis of oxidation-responsive amphiphilic diblock copolypeptoids

9 (PMeSPG- $b$-PSar) was presented using the ring opening polymerization of $N$-substituted

10 glycine $N$-thiocarboxyanhydrides under mild conditions. The hydrophobic PMeSPG bearing

11 thioether side-chains has the repeating unit transformed from methionine, an essential human

12 amino acid, and can be transformed into hydrophilic poly(amino acid) with sulfoxide

13 side-chains under the action of ROS generated chemically or photochemically. Polymersomes 
1 were then prepared from PMeSPG- $b$-PSar using nanoprecipitation and double emulsion

2 methods. We have shown that the polymersomes PMeSPG- $b$-PSar can be destroyed by $\mathrm{H}_{2} \mathrm{O}_{2}$

3 added in the aqueous dispersion in the time scale from several minutes to several hours. It

4 was also demonstrated that with the aid of a photosensitizer the rupture of giant

5 polymersomes can be triggered by light with high spatial and temporal precision. The light

6 source from standard white lamps or visible light laser also allows broad applicability with

7 standard laboratory equipment. The cell viability test on the polymersomes PMeSPG- $b$-PSar

8 confirmed their biocompatibility for possible bio-related applications.

9 Even though the $\mathrm{H}_{2} \mathrm{O}_{2}$ concentration used here is on the order of millimole and greatly

10 exceeds the micromolar level of $\mathrm{H}_{2} \mathrm{O}_{2}$ in vivo, encapsulation of oxidant-generating enzymes

11 can be envisioned, such as glucose-, lactose-, or uric acid-oxidase, ${ }^{22}$ to produce in situ high

12 concentration of $\mathrm{H}_{2} \mathrm{O}_{2}$ at the targeted sites where the corresponding substrate is present in

13 sufficient quantity. For the light-sensitive vesicle rupture, with judicious choice of the

14 photosensitizer, the light source can be extended to the near-infrared range. All these

15 possibilities are very promising for controlled drug delivery without damaging surrounding

16 cells or organelles. It will also be possible to combine chemotherapy and photodynamic

17 therapy with the use of photosensitizers. These systems can also be used for the design of

18 polymersome-based micro/nano-reactors, biosensors and biodetectors. 
1 The Supporting Information is available free of charge on the ACS Publications website at

$2 \quad$ DOI:...

3 Materials and methods, experimental details, characterization data (PDF).

4 Videos of vesicle disruption under the stimuli of $\mathrm{H}_{2} \mathrm{O}_{2}$ or light irradiation (AVI).

5

6 AUTHOR INFORMATION

7 Corresponding Author

$8 \quad *$ Email: min-hui.li@,chimieparistech.psl.eu

$9 \quad *$ Email: lingjun@zju.edu.cn

10 Present Address

$11{ }^{\perp}$ Shanghai Key Laboratory of Advanced Polymeric Materials, Key Laboratory for Ultrafine

12 Materials of Ministry of Education, School of Materials Science and Engineering, East China

13 University of Science and Technology, Shanghai 200237, China.

\section{Author Contributions}

15 M.-H.L., J.L. and Y.D. designed the research. Y.D. performed the research. H.C. and S.T.

16 contributed to the cryo-EM characterization. X.T. gave assistance in polymerization and 
1 surface treatment of coverslips. F.C. synthesized the photosensitizer. M.-H.L. and Y.D. wrote

2 the paper.

3 Notes

4 The authors declare no competing financial interest.

5

\section{ACKNOWLEDGMENTS}

7 We acknowledge the French National Research Agency (project ANR-16-CE29-0028) and

8 the National Natural Science Foundation of China (project 21528402 and 21674091) for

9 financial support. Y.D. thanks the China Scholarship Council for funding his Ph.D.

10 scholarship in France. We thank Yixian Wu and Patrick Keller for fruitful discussions. 


\section{REFERENCES}

2 (1) Discher, D. E.; Eisenberg, A., Polymer Vesicles. Science 2002, 297 (5583), 967-973.

3 (2) Discher, D. E.; Ortiz, V.; Srinivas, G.; Klein, M. L.; Kim, Y.; Christian, D.; Cai, S.;

4 Photos, P.; Ahmed, F., Emerging Applications of Polymersomes in Delivery: From

5 Molecular Dynamics to Shrinkage of Tumors. Prog. Polym. Sci. 2007, 32 (8-9), 838-857.

6 (3) Lee, J. S.; Feijen, J., Polymersomes for Drug Delivery: Design, Formation and 7 Characterization. J. Control. Release 2012, 161 (2), 473-483.

8 (4) Marguet, M.; Bonduelle, C.; Lecommandoux, S., Multicompartmentalized Polymeric

9 Systems: Towards Biomimetic Cellular Structure and Function. Chem. Soc. Rev. 2013, 42 $10 \quad(2), 512-29$.

11 (5) Schoonen, L.; van Hest, J. C. M., Compartmentalization Approaches in Soft Matter

12 Science: From Nanoreactor Development to Organelle Mimics. Adv. Mater. 2016, 28 (6), $13 \quad 1109-1128$.

14 (6) Li, M.-H.; Keller, P., Stimuli-Responsive Polymer Vesicles. Soft Matter 2009, 5 (5), $15 \quad 927-937$.

16 (7) Du, J. Z.; O'Reilly, R. K., Advances and Challenges in Smart and Functional Polymer 17 Vesicles. Soft Matter 2009, 5 (19), 3544-3561. 
1 (8) Meng, F. H.; Zhong, Z. Y.; Feijen, J., Stimuli-Responsive Polymersomes for

2 Programmed Drug Delivery. Biomacromolecules 2009, 10 (2), 197-209.

3 (9) Kim, K. T.; Meeuwissen, S. A.; Nolte, R. J. M.; van Hest, J. C. M., Smart

4 Nanocontainers and Nanoreactors. Nanoscale 2010, 2 (6), 844-858.

5 (10)Deng, Y.; Ling, J.; Li, M.-H., Physical Stimuli-Responsive Liposomes and 6 Polymersomes as Drug Delivery Vehicles Based on Phase Transitions in the Membrane.

$7 \quad$ Nanoscale 2018, 10, 6781-6800.

8 (11)Hu, X.; Zhang, Y.; Xie, Z.; Jing, X.; Bellotti, A.; Gu, Z., Stimuli-Responsive 9 Polymersomes for Biomedical Applications. Biomacromolecules 2017, 18 (3), 649-673.

10 (12)Wang, X.; Liu, G.; Hu, J.; Zhang, G.; Liu, S., Concurrent Block Copolymer 11 Polymersome Stabilization and Bilayer Permeabilization by Stimuli-Regulated "Traceless" 12 Crosslinking. Angew. Chem. Int. Ed. 2014, 53 (12), 3138-3142.

13 (13)Wang, X.; Hu, J.; Liu, G.; Tian, J.; Wang, H.; Gong, M.; Liu, S., Reversibly Switching 14 Bilayer Permeability and Release Modules of Photochromic Polymersomes Stabilized by 15 Cooperative Noncovalent Interactions. J. Am. Chem. Soc. 2015, 137 (48), 15262-15275.

16 (14)García, M. C., 13 - Stimuli-Responsive Polymersomes for Drug Delivery Applications. 17 In Stimuli Responsive Polymeric Nanocarriers for Drug Delivery Applications, Makhlouf, A.

18 S. H.; Abu-Thabit, N. Y., Eds. Woodhead Publishing: 2019; pp 345-392. 
1 (15)Lux, C. d. G.; Joshi-Barr, S.; Trung, N.; Mahmoud, E.; Schopf, E.; Fomina, N.;

2 Almutairi, A., Biocompatible Polymeric Nanoparticles Degrade and Release Cargo in 3 Response to Biologically Relevant Levels of Hydrogen Peroxide. J. Am. Chem. Soc. 2012, $4 \quad 134(38), 15758-15764$.

5 (16) Shim, M. S.; Xia, Y., A Reactive Oxygen Species (ROS)-Responsive Polymer for Safe,

6 Efficient, and Targeted Gene Delivery in Cancer Cells. Angew. Chem. Int. Ed. 2013, 52 (27),

$7 \quad 6926-6929$.

8 (17)Deng, Z.; Hu, J.; Liu, S., Reactive Oxygen, Nitrogen, and Sulfur Species 9 (RONSS)-Responsive Polymersomes for Triggered Drug Release. Macromol. Rapid 10 Commun. 2017, $38(11)$, e1600685.

11 (18)Liou, G.-Y.; Storz, P., Reactive Oxygen Species in Cancer. Free Radical Res. 2010, 44 12 (5), 479-496.

13 (19)Halliwell, B.; Clement, M. V.; Long, L. H., Hydrogen Peroxide in the Human Body. 14 FEBS Lett. 2000, $486(1), 10-13$.

15 (20)Ohshima, H.; Tatemichi, M.; Sawa, T., Chemical Basis of Inflammation-Induced 16 Carcinogenesis. Arch. Biochem. Biophys. 2003, 417 (1), 3-11. 
1 (21)Doskey, C. M.; Buranasudja, V.; Wagner, B. A.; Wilkes, J. G.; Du, J.; Cullen, J. J.;

2 Buettner, G. R., Tumor Cells Have Decreased Ability to Metabolize H2O2: Implications for

3 Pharmacological Ascorbate in Cancer Therapy. Redox Bio. 2016, 10, 274-284.

4 (22)Ikeda, M.; Tanida, T.; Yoshii, T.; Kurotani, K.; Onogi, S.; Urayama, K.; Hamachi, I., 5 Installing Logic-Gate Responses to a Variety of Biological Substances in Supramolecular 6 Hydrogel-Enzyme Hybrids. Nat. Chem. 2014, 6 (6), 511-518.

7 (23) Vasdekis, A. E.; Scott, E. A.; O'Neil, C. P.; Psaltis, D.; Hubbell, J. A., Precision 8 Intracellular Delivery Based on Optofluidic Polymersome Rupture. ACS Nano 2012, 6 (9), $9 \quad 7850-7857$.

10 (24)Napoli, A.; Boerakker, M. J.; Tirelli, N.; Nolte, R. J. M.; Sommerdijk, N.; Hubbell, J. A., 11 Glucose-oxidase based self-destructing polymeric vesicles. Langmuir 2004, 20 (9), $12 \quad 3487-3491$.

13 (25)Xu, S.; Ng, G.; Xu, J.; Kuchel, R. P.; Yeow, J.; Boyer, C., 2-(Methylthio)ethyl 14 Methacrylate: A Versatile Monomer for Stimuli Responsiveness and Polymerization-Induced 15 Self-Assembly in the Presence of Air. ACS Macro Lett. 2017, 6 (11), 1237-1244.

16 (26)He, H.; Ji, S.; He, Y.; Zhu, A.; Zou, Y.; Deng, Y.; Ke, H.; Yang, H.; Zhao, Y.; Guo, Z.;

17 Chen, H., Photoconversion-Tunable Fluorophore Vesicles for Wavelength-Dependent 18 Photoinduced Cancer Therapy. Adv. Mater. 2017, 29 (19), e1606690. 
1 (27)Lee, S. H.; Gupta, M. K.; Bang, J. B.; Bae, H.; Sung, H.-J., Current Progress in Reactive

2 Oxygen Species (ROS)-Responsive Materials for Biomedical Applications. Adv. Healthc.

$3 \quad$ Mater. 2013, 2 (6), 908-915.

4 (28)Song, C. C.; Du, F. S.; Li, Z. C., Oxidation-Responsive Polymers for Biomedical 5 Applications. J. Mater. Chem. B 2014, 2 (22), 3413-3426.

6 (29)El-Mohtadi, F.; d'Arcy, R.; Tirelli, N., Oxidation-Responsive Materials: Biological

7 Rationale, State of the Art, Multiple Responsiveness, and Open Issues. Macromol. Rapid 8 Commun. 2019, $40(1), 1800699$.

9 (30)Vo, C. D.; Kilcher, G.; Tirelli, N., Polymers and Sulfur: What are Organic Polysulfides 10 Good for? Preparative Strategies and Biological Applications. Macromol. Rapid Commun. $112009,30(4-5), 299-315$.

12 (31)Sobotta, F. H.; Hausig, F.; Harz, D. O.; Hoeppener, S.; Schubert, U. S.; Brendel, J. C.,

13 Oxidation-Responsive Micelles by a One-Pot Polymerization-Induced Self-Assembly 14 Approach. Polym. Chem. 2018, 9 (13), 1593-1602.

15 (32)Zhang, Y.; He, P.; Liu, X.; Zhang, H.; Yang, H.; Xiao, C.; Chen, X., Synthesis of 16 Pegylated Alternating Copolymer Bearing Thioether Pendants for Oxidation Responsive 17 Drug Delivery. Eur. Polym. J. 2018, 107, 308-314. 
1 (33)Ke, W.; Li, J.; Mohammed, F.; Wang, Y.; Tou, K.; Liu, X.; Wen, P.; Kinoh, H.; Anraku,

2 Y.; Chen, H.; Kataoka, K.; Ge, Z., Therapeutic Polymersome Nanoreactors with

3 Tumor-Specific Activable Cascade Reactions for Cooperative Cancer Therapy. ACS Nano

$4 \quad 2019,13(2), 2357-2369$.

5 (34)Cao, W.; Wang, L.; Xu, H., Selenium/Tellurium Containing Polymer Materials in

6 Nanobiotechnology. Nano Today 2015, 10 (6), 717-736.

7 (35)He, H.; Zhuang, W.; Ma, B.; Su, X.; Yu, T.; Hu, J.; Chen, L.; Peng, R.; Li, G.; Wang, Y.,

8 Oxidation-Responsive and Aggregation-Induced Emission Polymeric Micelles with

9 Two-Photon Excitation for Cancer Therapy and Bioimaging. ACS Biomaterials Science \&

$10 \quad$ Engineering 2019.

11 (36)Lee, D.; Bae, S.; Ke, Q.; Lee, J.; Song, B.; Karumanchi, S. A.; Khang, G.; Choi, H. S.;

12 Kang, P. M., Hydrogen Peroxide-Responsive Copolyoxalate Nanoparticles for Detection and

13 Therapy of Ischemia-Reperfusion Injury. J. Control. Release 2013, 172 (3), 1102-1110.

14 (37)Deng, Z.; Qian, Y.; Yu, Y.; Liu, G.; Hu, J.; Zhang, G.; Liu, S., Engineering Intracellular

15 Delivery Nanocarriers and Nanoreactors from Oxidation-Responsive Polymersomes via

16 Synchronized Bilayer Cross-Linking and Permeabilizing Inside Live Cells. J. Am. Chem. Soc.

17 2016, $138(33)$, 10452-10466. 
1 (38)Tan, J.; Deng, Z.; Liu, G.; Hu, J.; Liu, S., Anti-Inflammatory Polymersomes of

2 Redox-Responsive Polyprodrug Amphiphiles with Inflammation-Triggered Indomethacin

3 Release Characteristics. Biomaterials 2018, 178, 608-619.

4 (39)Napoli, A.; Valentini, M.; Tirelli, N.; Muller, M.; Hubbell, J. A., Oxidation-Responsive $5 \quad$ Polymeric Vesicles. Nat. Mater. 2004, 3 (3), 183-189.

6 (40)Herzberger, J.; Fischer, K.; Leibig, D.; Bros, M.; Thiermann, R.; Frey, H., 7 Oxidation-Responsive and "Clickable" Poly(ethylene glycol) via Copolymerization of 8 2-(Methylthio)ethyl Glycidyl Ether. J. Am. Chem. Soc. 2016, 138 (29), 9212-9223.

9 (41)Rodriguez, A. R.; Kramer, J. R.; Deming, T. J., Enzyme-Triggered Cargo Release from 10 Methionine Sulfoxide Containing Copolypeptide Vesicles. Biomacromolecules 2013, 14 (10), $11 \quad 3610-3614$.

12 (42)Kramer, J. R.; Deming, T. J., Reversible Chemoselective Tagging and Functionalization 13 of Methionine Containing Peptides. Chem. Commun. 2013, 49 (45), 5144-5146.

14 (43) Yu, S.; Wang, C.; Yu, J.; Wang, J.; Lu, Y.; Zhang, Y.; Zhang, X.; Hu, Q.; Sun, W.; He, 15 C.; Chen, X.; Gu, Z., Injectable Bioresponsive Gel Depot for Enhanced Immune Checkpoint 16 Blockade. Adv. Mater. 2018, e1801527. 
1 (44)Fu, X.; Ma, Y.; Shen, Y.; Fu, W.; Li, Z., Oxidation-Responsive OEGylated

2 Poly-L-cysteine and Solution Properties Studies. Biomacromolecules 2014, 15 (3), $3 \quad 1055-1061$.

4 (45)Liu, H.; Wang, R.; Wei, J.; Cheng, C.; Zheng, Y.; Pan, Y.; He, X.; Ding, M.; Tan, H.;

5 Fu, Q., Conformation-Directed Micelle-to-Vesicle Transition of Cholesterol-Decorated

6 Polypeptide Triggered by Oxidation. J. Am. Chem. Soc. 2018, 140 (21), 6604-6610.

7 (46) Yan, B.; Zhang, Y.; Wei, C.; Xu, Y., Facile Synthesis of ROS-Responsive Biodegradable 8 Main Chain Poly(carbonate-thioether) Copolymers. Polym. Chem. 2018, 9 (7), 904-911.

9 (47)Chan, B. A.; Xuan, S.; Li, A.; Simpson, J. M.; Sternhagen, G. L.; Yu, T.; Darvish, O. A.; 10 Jiang, N.; Zhang, D., Polypeptoid Polymers: Synthesis, Characterization, and Properties. 11 Biopolymers 2018, 109 (1), e23070.

12 (48)Lahasky, S. H.; Hu, X.; Zhang, D., Thermoresponsive Poly(alpha-peptoid)s: Tuning the

13 Cloud Point Temperatures by Composition and Architecture. ACS Macro Lett. 2012, 1 (5), $14 \quad 580-584$.

15 (49)Fetsch, C.; Flecks, S.; Gieseler, D.; Marschelke, C.; Ulbricht, J.; van Pee, K. H.; 16 Luxenhofer, R., Self-Assembly of Amphiphilic Block Copolypeptoids with C-2-C-5 Side 17 Chains in Aqueous Solution. Macromol. Chem. Phys. 2015, 216 (5), 547-560. 
1 (50)Secker, C.; Brosnan, S. M.; Luxenhofer, R.; Schlaad, H., Poly(alpha-Peptoid)s Revisited:

2 Synthesis, Properties, and Use as Biomaterial. Macromol. Biosci. 2015, 15 (7), 881-891.

3 (51)Li, A.; Zhang, D., Synthesis and Characterization of Cleavable Core-Cross-Linked

4 Micelles Based on Amphiphilic Block Copolypeptoids as Smart Drug Carriers.

5 Biomacromolecules 2016, 17 (3), 852-861.

6 (52)Ulbricht, J.; Jordan, R.; Luxenhofer, R., On the Biodegradability of Polyethylene Glycol,

7 Polypeptoids and Poly(2-Oxazoline)s. Biomaterials 2014, 35 (17), 4848-4861.

8 (53)Heller, P.; Hobernik, D.; Laechelt, U.; Schinnerer, M.; Weber, B.; Schmidt, M.; Wagner,

9 E.; Bros, M.; Barz, M., Combining Reactive Triblock Copolymers with Functional

10 Cross-Linkers: A Versatile Pathway to Disulfide Stabilized-Polyplex Libraries and Their

11 Application as PDNA Vaccines. J. Control. Release 2017, 258, 146-160.

12 (54)Birke, A.; Huesmann, D.; Kelsch, A.; Weilbacher, M.; Xie, J.; Bros, M.; Bopp, T.;

13 Becker, C.; Landfester, K.; Barz, M., Polypeptoid-block-Polypeptide Copolymers: Synthesis,

14 Characterization, and Application of Amphiphilic Block Copolypept(o)ides in Drug

15 Formulations and Miniemulsion Techniques. Biomacromolecules 2014, 15 (2), 548-557.

16 (55)Klinker, K.; Schafer, O.; Huesmann, D.; Bauer, T.; Capeloa, L.; Braun, L.; Stergiou, N.;

17 Schinnerer, M.; Dirisala, A.; Miyata, K.; Osada, K.; Cabral, H.; Kataoka, K.; Barz, M.,

18 Secondary-Structure-Driven Self-Assembly of Reactive Polypept(o)ides: Controlling Size, 
1 Shape, and Function of Core Cross-Linked Nanostructures. Angew. Chem. Int. Ed. 2017, 56

2 (32), 9608-9613.

3 (56)Maurer, P. H.; Subrahmanyam, D.; Katchalski, E.; Blout, E. R., Antigenicity of

4 Polypeptides (Poly Alpha Amino Acids). The Journal of Immunology 1959, 83 (2), 193-197.

5 (57) Sela, M., Immunological Studies with Synthetic Polypeptides. In Advances in

6 Immunology, Dixon, F. J.; Humphrey, J. H., Eds. Academic Press: 1966; Vol. 5, pp 29-129.

7 (58)Huesmann, D.; Sevenich, A.; Weber, B.; Barz, M., A Head-to-Head Comparison of

8 Poly(sarcosine) and Poly(ethylene glycol) in Peptidic, Amphiphilic Block Copolymers.

$9 \quad$ Polymer 2015, 67, 240-248.

10 (59)Birke, A.; Ling, J.; Barz, M., Polysarcosine-Containing Copolymers: Synthesis, 11 Characterization, Self-Assembly, and Applications. Prog. Polym. Sci. 2018, 81, 163-208.

12 (60)Tanisaka, H.; Kizaka-Kondoh, S.; Makino, A.; Tanaka, S.; Hiraoka, M.; Kimura, S.,

13 Near-Infrared Fluorescent Labeled Peptosome for Application to Cancer Imaging.

14 Bioconjugate Chem. 2008, 19 (1), 109-117.

15 (61)Deng, Y. W.; Zou, T.; Tao, X. F.; Semetey, V.; Trepout, S.; Marco, S.; Ling, J.; Li, M.

16 H., Poly(epsilon-caprolactone)-block-Polysarcosine by Ring-Opening Polymerization of

17 Sarcosine N-Thiocarboxyanhydride: Synthesis and Thermoresponsive Self-Assembly.

18 Biomacromolecules 2015, $16(10), 3265-3274$. 
1 (62)Gaitzsch, J.; Karu, K.; Battaglia, G., Peptoidosomes as Nanoparticles from Amphiphilic

2 Block Alpha-Peptoids Using Solid-Phase-Synthesis. Eur. Polym. J. 2015, 73, 447-454.

3 (63)Fetsch, C.; Gaitzsch, J.; Messager, L.; Battaglia, G.; Luxenhofer, R., Self-Assembly of

4 Amphiphilic Block Copolypeptoids - Micelles, Worms and Polymersomes. Scientific reports $5 \quad \mathbf{2 0 1 6}, 6,33491$.

6 (64) Varlas, S.; Georgiou, P. G.; Bilalis, P.; Jones, J. R.; Hadjichristidis, N.; O’Reilly, R. K.,

7 Poly(sarcosine)-Based Nano-Objects with Multi-Protease Resistance by Aqueous

8 Photoinitiated Polymerization-Induced Self-Assembly (Photo-PISA). Biomacromolecules $9 \quad 2018,19(11), 4453-4462$.

10 (65)Jiang, X.; Spencer, R. K.; Sun, J.; Ophus, C.; Zuckermann, R. N.; Downing, K. H.;

11 Balsara, N. P., Resolving the Morphology of Peptoid Vesicles at the $1 \mathrm{~nm}$ Length Scale

12 Using Cryogenic Electron Microscopy. J. Phys. Chem. B 2019, 123 (5), 1195-1205.

13 (66)Szatrowski, T. P.; Nathan, C. F., Production of Large Amounts of Hydrogen-Peroxide by 14 Human Tumor-Cells. Cancer Res. 1991, 51 (3), 794-798.

15 (67)Wilson, D. A.; Nolte, R. J.; van Hest, J. C., Autonomous Movement of Platinum-Loaded 16 Stomatocytes. Nat. Chem. 2012, 4 (4), 268-274. 
1 (68)Tu, Y.; Peng, F.; White, P. B.; Wilson, D. A., Redox-Sensitive Stomatocyte Nanomotors:

2 Destruction and Drug Release in the Presence of Glutathione. Angew. Chem. Int. Ed. 2017, $356(26), 7620-7624$.

4 (69)Dolmans, D.; Fukumura, D.; Jain, R. K., Photodynamic Therapy for Cancer. Nat. Rev.

$5 \quad$ Cancer 2003, 3 (5), 380-387.

6 (70)Zhou, Z.; Song, J.; Nie, L.; Chen, X., Reactive Oxygen Species Generating Systems 7 Meeting Challenges of Photodynamic Cancer Therapy. Chem. Soc. Rev. 2016, 45 (23), $8 \quad 6597-6626$.

9 (71)Yu, G.; Yu, S.; Saha, M. L.; Zhou, J.; Cook, T. R.; Yung, B. C.; Chen, J.; Mao, Z.;

10 Zhang, F.; Zhou, Z.; Liu, Y.; Shao, L.; Wang, S.; Gao, C.; Huang, F.; Stang, P. J.; Chen, X., 11 A Discrete Organoplatinum(II) Metallacage as a Multimodality Theranostic Platform for 12 Cancer Photochemotherapy. Nat. Comm. 2018, 9 (1), 4335.

13 (72)Bi, C.; Chen, J.; Chen, Y.; Song, Y.; Li, A.; Li, S.; Mao, Z.; Gao, C.; Wang, D.; 14 Möhwald, H.; Xia, H., Realizing a Record Photothermal Conversion Efficiency of Spiky 15 Gold Nanoparticles in the Second Near-Infrared Window by Structure-Based Rational 16 Design. Chem. Mater. 2018, 30 (8), 2709-2718.

17 (73)Zhu, H.; Wang, H.; Shi, B.; Shangguan, L.; Tong, W.; Yu, G.; Mao, Z.; Huang, F., 18 Supramolecular Peptide Constructed by Molecular Lego Allowing Programmable 19 Self-Assembly for Photodynamic Therapy. Nat. Comm. 2019, 10 (1), 2412. 
1 (74)Zuckermann, R. N.; Kerr, J. M.; Kent, S. B. H.; Moos, W. H., Efficient Method for the

2 Preparation of Peptoids Oligo(N-substituted glycines) by Submonomer Solid-Phase

3 Synthesis. J. Am. Chem. Soc. 1992, 114 (26), 10646-10647.

4 (75)Kricheldorf, H. R., Polypeptides and 100 years of chemistry of alpha-amino acid

5 N-carboxyanhydrides. Angew. Chem. Int. Ed. 2006, 45 (35), 5752-5784.

6 (76)Tao, X.; Li, M.-H.; Ling, J., $\alpha$-Amino Acid N-Thiocarboxyanhydrides: A Novel

7 Synthetic Approach toward Poly( $\alpha$-amino acid)s. Eur. Polym. J. 2018, 109, 26-42.

8 (77)Kricheldorf, H. R.; Sell, M.; Schwarz, G., Primary Amine-Initiated Polymerizations of

9 Alpha-Amino Acid N-Thiocarbonic Acid Anhydrosulfide. J. Macromol. Sci., Pure Appl.

10 Chem. 2008, 45 (6), 425-430.

11 (78)Tao, X.; Deng, Y.; Shen, Z.; Ling, J., Controlled Polymerization of N-Substituted

12 Glycine N-Thiocarboxyanhydrides Initiated by Rare Earth Borohydrides toward Hydrophilic

13 and Hydrophobic Polypeptoids. Macromolecules 2014, 47 (18), 6173-6180.

14 (79)Tao, X.; Zheng, B.; Kricheldorf, H. R.; Ling, J., Are N-Substituted Glycine

15 N-Thiocarboxyanhydride Monomers Really Hard to Polymerize? J. Polym. Sci., Part A:

16 Polym. Chem. 2017, 55 (3), 404-410.

17 (80)Cao, J.; Siefker, D.; Chan, B. A.; Yu, T.; Lu, L.; Saputra, M. A.; Fronczek, F. R.; Xie,

18 W.; Zhang, D., Interfacial Ring-Opening Polymerization of Amino-Acid-Derived 
1 N-Thiocarboxyanhydrides Toward Well-Defined Polypeptides. ACS Macro Lett. 2017, 6 (8),

$2836-840$.

3 (81)Siefker, D.; Williams, A. Z.; Stanley, G. G.; Zhang, D., Organic Acid Promoted 4 Controlled Ring-Opening Polymerization of $\alpha$-Amino Acid-Derived 5 N-thiocarboxyanhydrides (NTAs) toward Well-defined Polypeptides. ACS Macro Lett. 2018, $6 \quad 7(10), 1272-1277$.

7 (82) Yamada, S.; Ikkyu, K.; Iso, K.; Goto, M.; Endo, T., Facile Synthesis of Polymethionine

8 Oxides through Polycondensation of Activated Urethane Derivative of Alpha-Amino Acid 9 and Their Application to Antifouling Polymer Against Proteins and Cells. Polym. Chem. $10 \quad 2015,6(10), 1838-1845$.

11 (83)Blanazs, A.; Armes, S. P.; Ryan, A. J., Self-Assembled Block Copolymer Aggregates:

12 From Micelles to Vesicles and their Biological Applications. Macromol. Rapid Commun. $132009,30(4-5), 267-277$.

14 (84)Bae, J.; Russell, T. P.; Hayward, R. C., Osmotically Driven Formation of Double 15 Emulsions Stabilized by Amphiphilic Block Copolymers. Angew. Chem. Int. Ed. Engl. 2014, $1653(31), 8240-8245$.

17 (85)Park, M.-K.; Jun, S.; Kim, I.; Jin, S.-M.; Kim, J.-G.; Shin, T. J.; Lee, E., Stepwise 18 Drug-Release Behavior of Onion-Like Vesicles Generated from Emulsification-Induced 
1 Assembly of Semicrystalline Polymer Amphiphiles. Adv. Funct. Mater. 2015, 25 (29), 2 4570-4579.

3 (86) Wang, X. Y.; Feng, X. Y.; Ma, G. P.; Zhang, D.; Chai, Y. H.; Ge, M. F.; Yao, L.,

4 Dual-Phase Separation in a Semiconfined System: Monodispersed Heterogeneous

5 Block-Copolymer Membranes for Cell Encoding and Patterning. Adv. Mater. 2017, 29 (19),

$6 \quad$ e1605932.

7 (87)Riske, K. A.; Sudbrack, T. P.; Archilha, N. L.; Uchoa, A. F.; Schroder, A. P.; Marques,

8 C. M.; Baptista, M. S.; Itri, R., Giant Vesicles under Oxidative Stress Induced by a 9 Membrane-Anchored Photosensitizer. Biophys. J. 2009, 97 (5), 1362-1370.

10 (88)Mabrouk, E.; Bonneau, S.; Jia, L.; Cuvelier, D.; Li, M.-H.; Nassoy, P., Photosensitization 11 of Polymer Vesicles: A Multistep Chemical Process Deciphered by Micropipette 12 Manipulation. Soft Matter 2010, 6 (19), 4863-4875.

13 (89)Robbins, G. P.; Jimbo, M.; Swift, J.; Therien, M. J.; Hammer, D. A.; Dmochowski, I. J., 14 Photoinitiated Destruction of Composite Porphyrin-Protein Polymersomes. J. Am. Chem. 15 Soc. 2009, $131(11), 3872-3874$.

16 (90)Kim, J. B.; Leonard, J. J.; Longo, F. R., Mechanistic study of the synthesis and spectral 17 properties of meso-tetraarylporphyrins. J. Am. Chem. Soc. 1972, 94 (11), 3986-3992. 


\section{Oxidation-Sensitive Polymersomes Based on Amphiphilic Diblock Copolypeptoids}

3 Amphiphilic diblock copolypeptoids with oxidation-responsive properties were synthesized,

4 which self-assembled into unilamellar vesicles. These vesicles can burst under the action of

5 reactive oxygen species (ROS) like the hydrogen peroxide, or the singlet oxygen produced by

6 light-activation of photosensitizer with spatiotemporal control.

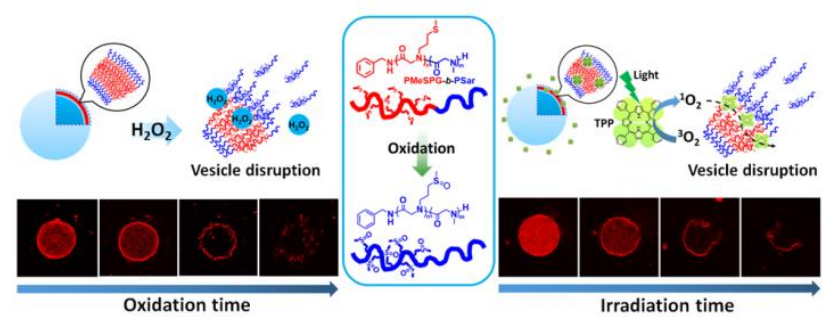

